\section{Sujeitos singulares e coletivos: experiência do projeto de extensão "Aproxima-Ação" em diálogo com Gramsci}

\author{
Andréa Pires Rocha \\ Universidade Estadual de Londrina, Brasil \\ drea_rocha@yahoo.com.br \\ (iD) orcid.org/0000-0003-4158-754
}

Sujetos y relaciones en extensión universitaria / Perspectivas
RECEPCIÓN: 29/04/20

ACEPTACIÓN FINAL: 20/05/20

\section{Resumo}

Refletimos sobre a concepção de sujeito que aderimos para o desenvolvimento de ações extensionistas a partir da experiência obtida pelo Projeto de Extensão "Aproxima-Ação: Direitos Humanos, Estatuto da Criança e do Adolescente (ECA) e Protagonismo" sob a luz de um diálogo com Gramsci. Apresentamos algumas confluências com Paulo Freire e outros autores, a partir da abordagem sobre processos de conscientização e empoderamento. Tecemos reflexões acerca de ações de extensão universitária no campo da educação em direitos humanos, problematizando os mecanismos de opressão que se mostram a partir das categorias raça, classe e gênero e a importância do estímulo da construção de consciência crítica, entendendo os sujeitos a partir de duas esferas: singular e coletiva. Defendemos que professores, estudantes e comunidade são igualmente sujeitos capazes de ensinar e aprender. Abordamos as nuances contra hegemônicas possíveis no contexto da universidade, colocando-a como vetor para a busca de mudanças sociais.

Palavras-chave: extensão universitária; Gramsci; cultura; contra-hegemonia; educação em direitos humanos
Singular and collective subjects: experience of the extension project "Aproxima-Ação" in dialogue with Gramsci

\section{Abstract}

We reflected on the conception of subjects we adhered to for the development of extension actions based on the experience obtained by the Extension Project "AproximaAção: Human Rights, Child and Adolescent Statute (ECA) and Protagonism" in the light of a dialogue with Gramsci. We present some confluences with Paulo Freire and other authors, from the approach on processes of awareness and empowerment. We weave reflections about university extension actions in the field of human rights education, problematizing the mechanisms of oppression that appear from the categories race, class and gender and the importance of stimulating the construction of critical awareness, understanding the subjects from two spheres: singular and collective. We argue that teachers, students and the community are equally capable of teaching and learning. We approach the possible counter-hegemonic nuances in the context of the university, placing it as a vector for the search for social changes.

Keywords: university extension; Gramsci; culture; counter-hegemonic; human rights education
Sujetos singulares y colectivos: experiencia del proyecto de extensión "Aproxima-Ação" en diálogo con Gramsci

\section{Resumen}

Reflexionamos sobre la concepción de temas a los que nos adherimos para el desarrollo de acciones de extensión basadas en la experiencia obtenida por el Proyecto de Extensión "Aproxima-Ação: Derechos Humanos, Estatuto de Niños y Adolescentes (ECA) y Protagonismo" a la luz de un diálogo con Gramsci. Presentamos algunas confluencias con Paulo Freire y otros autores desde el enfoque de los procesos de concienciación y empoderamiento. Tejemos reflexiones sobre las acciones de extensión universitaria en el campo de la educación en derechos humanos y problematizamos los mecanismos de opresión que surgen de las categorías raza, clase y género, y la importancia de estimular la construcción de conciencia crítica, entendiendo los temas desde dos esferas: singular y colectiva. Argumentamos que los maestros, los estudiantes y la comunidad son igualmente capaces de enseñar y aprender. Abordamos los posibles matices contrahegemónicos en el contexto de la universidad, ubicándolo como un vector para la búsqueda de cambios sociales.

Palabras clave: extensión universitaria; Gramsci; cultura; contrahegemonía; educación en derechos humanos

Para citación de este artículo: Pires Rocha, A. (2020) Sujeitos singulares e coletivos: experiência do projeto de extensão "Aproxima-Ação" em diálogo com Gramsci. +E: Revista de Extensión Universitaria, 10(12.Ene-Jun), 1-23. doi: 10.14409/extension.v10i12.Ene-Jun.8974. 


\section{Palavras iniciais}

Desenvolvemos ao longo da trajetória profissional, como Assistente Social e, agora como professora do Departamento de Serviço Social de uma universidade pública, pesquisas que situam a questão do jovem atingido de maneira direta pelas expressões mais duras do Estado neoliberal de cunho penal, logo, daqueles que sofreram inúmeras violações de direitos ao longo da vida e que, na adolescência, tem a força de trabalho explorada pelo narcotráfico e/ ou comete outros tipos de delitos, controlados por um conjunto de medidas estatais, o que chamamos de cidadania invertida. Neste contexto apontamos que o juvenicídio brasileiro (Rocha, 2018) é composto pelo racismo estrutural - e os fenômenos decorrentes dele, a exemplo do genocídio da juventude negra e pobre - , a guerra às drogas e o encarceramento em massa, as quais simulam medidas que dizem enfrentar a violência urbana, quando na verdade se utilizam da seletividade penal e de medidas que historicamente tem sido cunhadas na criminalização dos negros e pobres, consolidada historicamente no país.

Por outro lado, em resposta às denúncias que levantamos por meio de pesquisas, decidimos atuar em extensão universitária na esfera da educação em Direitos Humanos por acreditarmos que a construção de consciência crítica é instrumento essencial em processos de tensões que esses direitos se situam. Isso também se deu a partir da percepção de que as denúncias decorrentes de pesquisas possuem um enorme cunho social, no entanto, o impacto disso aumenta, quando vinculado a ações diretas voltadas à comunidade como um todo. Desta forma, partimos do pressuposto de que ensino, pesquisa e extensão, quando caminham juntas, geram processos muito maiores e ampliam aspectos contra-hegemônicos da universidade pública. Ao desenvolvermos o Projeto "Aproxima-Ação: Direitos Humanos, Estatuto da Criança e do Adolescente e Protagonismo", financiado pelo edital MEC-PROEXT $2015,{ }^{1}$ nosso objetivo foi difundir esses direitos, incentivando os participantes a tornaremse multiplicadores em ações cotidianas. Para isso atuamos em três frentes: a) Oficinas em Londrina/ $\mathrm{PR}^{2}$ e região; b) Curso de Capacitação; c) Disseminação dos resultados a partir de eventos e o lançamento de uma cartilha.

Essa experiência foi desenvolvida e analisada por meio de categorias assentadas no materialismo histórico e dialético. Portanto, optamos por apresentar no presente artigo a concepção de sujeito que aderimos sob a luz da perspectiva gramsciana. Para isso, apontamos na primeira parte do texto os mecanismos de opressão que se mostram a partir das questões de raça, de classe e de gênero, que estão vinculadas dialeticamente e se materializam no contexto da exploração capitalista, do racismo e do patriarcado. Apontamos o quanto esses mecanismos de opressão se assentam na esfera da ideologia e sustentam elementos superestruturais e estruturais, os quais mantém a lógica perversa da sociabilidade burguesa. Mediante este panorama, visualizamos a importância do estímulo da construção de cons-

1) O Programa de Extensão Universitária (ProExt), é vinculado ao Ministério da Educação e foi criado em 2003 , tendo como principal objetivo "apoiar as instituições públicas de ensino superior no desenvolvimento de programas ou projetos de extensão que contribuam para a implementação de políticas públicas (...) abrange a extensão universitária com ênfase na inclusão social" (Brasil, 2020a).Com o recurso do MEC-PROEXT pudemos oferecer oito bolsas de graduação e adquirir materiais como notebooks, projetores, desktops, geladeira, entre outros.

2) Londrina é munícipio situado no norte do Estado do Paraná, região Sul do Brasil. Segundo o IBGE - Instituto Brasileiro de Geografia e Estatística, a população estimada é de 569.733. É um município que o desempenho econômico se centra no Agronegócio da região e também em indústrias, no entanto, mantém muita pobreza e desigualdade de renda. 
ciência crítica e do protagonismo popular, o que colocamos como desafio da educação em direitos humanos. Desta forma, tecemos reflexões sobre a perspectiva gramsciana sobre sujeitos singulares e coletivos como potenciais transformadores da história.

\section{Educação em direitos humanos sob as lentes das categorias classe, raça e gênero}

A conjuntura atual é determinada pelo agravamento da crise do capital, fortalecimento da política neoliberal, desmontes desenfreados das políticas sociais e fortalecimento do Estado penal, levando ao recrudescimento das expressões da questão social o que tem tornando a vida da classe trabalhadora cada dia mais difícil (Harvey, 2011; Wacquant, 2014; Rocha, 2005; 2018). Obstante a isso, vemos que as esferas dos poderes legislativo, executivo e judiciário, têm demonstrado de maneira clara retrocessos no que se refere a garantia dos Direitos Humanos duramente conquistados no Brasil, na América Latina e no mundo como um todo. Ao olharmos para o Brasil visualizamos o ataque frontal e direto à democracia, que teve sua retomada3 no processo que levou ao golpe-parlamentar materializado no impeachment da presidenta Dilma Rousseff.

E, em um contexto de instabilidade econômica e social que, no final de 2018, levou à vitória de Jair Messias Bolsonaro, apoiando-se em uma campanha centrada na retórica conservadora, assentada em uma concepção equivocada sobre os Direitos Humanos, camuflada pela missão de se combater a corrupção e fundada no recente fenômeno das fake news. A partir daí os retrocessos são sem igual, ou seja, o mínimo de garantia de direitos sociais e políticos conquistados na Constituição de 1988 são desmontados por reformas diretas. Neste sentido não poderíamos deixar de problematizar os limites da sociabilidade burguesa, que se centra na manutenção das relações de produção e do acúmulo de capital, em detrimento da vida humana4. Por isso, na sequência abordaremos os mecanismos de opressão, seu necessário combate e a extensão universitária na esfera da Educação em Direitos Humanos como uma interessante possibilidade de atuação social da universidade.

\section{Os mecanismos de opressão e a luta por Direitos Humanos}

Em linhas gerais problematizamos o lugar que o direito ocupa nas relações superestruturais que sustentam o capitalismo, pois mesmo quando positivado em normativas e legislações, essas estão em constante disputa e nos momentos de agravamento da crise, a

3) É essencial compreendermos, a realidade brasileira sempre girou em torno da ausência de democracia, com momentos de mais opressão e outros com algum arremedo democrático. Sem sombra de dúvidas, o período da ditadura militar estabelecida no Brasil em 1964 foi, até então, o contexto com maior recuo da democracia e avanço da opressão, portanto, no período ditatorial, que durou 20 anos, os movimentos sociais foram imprescindíveis. Os militantes/ativistas sofreram diferente monta de violência e perseguição, mas a persistência destes movimentos e seus sujeitos coletivos, em conjunto com o fortalecimento de partidos políticos de esquerda, foram elementos essenciais para a superação daquele período sombrio do Brasil.

4) No momento em que escrevemos este artigo, estamos em isolamento social por conta da pandemia do coronavírus e a rápida disseminação da enfermidade COVID-19, que desde dezembro de 2019 tem se expandido pelo mundo. A humanidade vive, no primeiro quadrimestre de 2020 , um de seus piores momentos, onde crise de saúde pública e do capitalismo acontecem ao mesmo tempo. No Brasil a situação está estarrecedora, à medida que o governo federal de Jair Bolsonaro, em postura negacionista implementa uma política genocida voltada a negros e pobres. Até o final de Maio de 2020 já foram 18 mil mortes no país. 
classe trabalhadora é a que mais sofre com os ataques. Desta forma, concordamos com Trindade (2011) ao apontar que a natureza dos Direitos Humanos é burguesa e sempre teve a propriedade privada como valor central, no entanto, o autor demonstra que historicamente as lutas operárias passaram a reivindicar que esses direitos se expandissem para a classe trabalhadora, direitos de igualdade de gênero e étnico/racial, entre outras, transformando-os em instrumentos reivindicatórios dos movimentos sociais. Entendemos que os Direitos $\mathrm{Hu}-$ manos, vistos transversalmente ao abranger direitos sociais, econômicos, políticos, civis e culturais, estão inseridos em uma arena de tensões, sofrendo ataques frontais na esfera da superestrutura a partir de determinantes ideologizados cunhados em discursos pautados no ódio e na intolerância, e na esfera estrutural no que tange aos desmontes concretos e implementação de legislações e projetos de lei que os colocam em risco iminente.

E, para manutenção desta lógica perversa, coexistem diferentes mecanismos de opressão, que se materializam nas questões de classe, raça/etnia e gênero. Em relação à classe social, estamos convictos de que o modo de produção capitalista e sua sociabilidade burguesa se assenta em contradições decorrentes da exploração da força de trabalho e da centralidade da propriedade privada, elementos esses que são a base das relações econômicas voltadas para a acumulação de alguns à custa da miséria de outros. Sistema esse justificado e sustentado pela ideologia que se materializa na superestrutura, envolvendo relações políticas e jurídicas. Além disso, com o agravamento da crise do capital, o Estado neoliberal de cunho penal se fortalece, utilizando-se da seletividade penal para o controle dos negros e pobres. No entanto, as relações capitalistas não acontecem sem o apoio de outros mecanismos de opressão, em especial, o racismo e o patriarcado, os quais, já estavam presentes em outros modos de produção, no entanto, persistiram ao longo da história e hoje são elementos essenciais para manutenção da ordem societária vigente.

Neste sentido, defendemos que a questão racial não pode ser vista como mero elemento coadjuvante da questão de classe, pois o racismo é estrutural e estruturante das relações sociais. Silvio Almeida (2018, p. 38) aponta que o racismo é estrutural por compor "o modo 'normal' com que se constituem as relações políticas, econômicas, jurídicas e até familiares". Lembremos que no contexto da sociedade mercantil, quando ainda o pensamento liberal se desenhava, o racismo foi instrumento essencial para o estabelecimento do colonialismo (Fanon, 2005; Achille, 2016) e a espoliação da população negra africana que foi escravizada em diferentes territórios. O escravismo colonial já subsidiava a consolidação do modo de produção capitalista e delineava as relações sociais brasileiras (Gorender, 2016). Ou seja, enquanto o continente europeu passava por revoluções burguesas que traziam mudanças significativas para as esferas da estrutura e superestrutura, o acúmulo de capital sustentavase em duas formas de exploração, a da força de trabalho dos negros escravizados e dos recursos naturais do continente americano, fortalecendo a nascente sociedade burguesa na esfera econômica. Enfim, como elucida Willians (2012), é inegável que a revolução industrial também se utilizou do racismo para sua consolidação.

Reforçamos, portanto, o entendimento de que o racismo estrutural foi, portanto, elemento delineador das relações sociais brasileiras, as quais desde o período colonial o utilizou para se justificar a escravização dos negros sequestrados do continente africano. E, após o estabelecimento da república liberal, foram inúmeras as legislações que fortaleceram a segregação e exclusão dos negros. Atualmente, a população negra, composta por pretos e pardos, 
é a mais vulnerável economicamente, mais excluída da rede de proteção social, a que mais sofre violência em suas diferentes expressões, que é mais atingida pelo encarceramento em massa. Desta forma, a discussão sobre o racismo e seu enfrentamento é essencial. E, como não poderíamos deixar de abordar, o patriarcado também interfere no que estamos chamando de sociabilidade burguesa:

"Na ordem patriarcal de gênero, o branco encontra sua segunda vantagem. Caso seja rico, encontra sua terceira vantagem, o que mostra que o poder é macho, branco e, de preferência, heterossexual". (Saffioti, 2004, p. 31)

As mulheres ainda enfrentam desafios inúmeros em decorrência do machismo e da violência de gênero, especialmente as mulheres negras, que são no Brasil as maiores vítimas de diferentes formas de exploração, inclusive do feminicídio. As categorias raça/etnia, gênero e classe são construídas historicamente, atingem a sociedade de forma coletiva, mas também se apresentam no cotidiano de maneira singular, podendo ser compreendidas a partir de reflexões que partem do individual, do como a realidade atinge os sujeitos individualmente $\mathrm{e}$ como esses processos se reverberam no coletivo, no que tange a reprodução ou desconstrução de valores.

\section{Extensão universitária como possibilidade para Educação em Direitos Humanos}

Observamos, portanto, que os mecanismos de opressão são naturalizados no cotidiano e fazem com que os sujeitos oprimidos, também se tornem opressores. A título de elaboração reflexiva, podemos pensar no homem negro, submetido à superexploração do trabalho, que ao chegar em casa, oprime sua companheira e filhos, contexto que elucida a relação entre diferentes mecanismos de opressão no contexto individual, singular e coletivo. Portanto, defendemos a essencialidade da desconstrução de discursos que perpetuam opressões decorrentes do racismo, do patriarcado e da exploração de classe. Obstante a isso, concordamos com Angela Davis quando afirma que ações devem decorrer de "esforços de reflexão, análise e organização que reconhecem as interconexões entre raça, classe gênero, sexualidade" (Davis, 2018, p. 33) pautando-se na tripla ameaça: racismo, sexismo e imperialismo. Reforçando que por trás do conceito da interseccionalidade há uma importante história de luta e diálogos que envolvem ativistas e intelectuais das academias. Para ela, o mais importante do debate é o diálogo entre as frentes, que deve culminar em uma "interseccionalidade de lutas" (p. 34).

Para tal, também nos apoiamos na reflexão de Gramsci, quando o pensador aponta que "a elaboração crítica é a consciência daquilo que somos realmente, isto é, um 'conhecete a ti mesmo' como produto do processo histórico até hoje desenvolvido" (1981, p. 12). Consciência crítica que só se desperta a partir de processos reflexivos pautados em perspectivas críticas, por isso, acreditamos que processos de educação em Direitos Humanos, situados na desconstrução de discursos ideologizados são essenciais para ações de extensão universitária. Essas reflexões devem chegar às classes populares, que vivenciam a opressão e a resistência de forma concomitante, no entanto, muitas vezes se iludem com discursos ideologizados, o que prejudica a construção de uma consciência coletiva acerca das violências que estão submetidas ou dos direitos que lhes são garantidos, havendo o que Chauí (1996, p. 43) chama de "mescla de conformismo e resistência". Situamos então 
o lugar da extensão universitária pois, a normativa brasileira mais recente a coloca como: "Art. $3^{\circ}$ (...) a atividade que se integra à matriz curricular e à organização da pesquisa, constituindo-se em processo interdisciplinar, político educacional, cultural, científico, tecnológico, que promove a interação transformadora entre as instituições de ensino superior e os outros setores da sociedade, por meio da produção e da aplicação do conhecimento, em articulação permanente com o ensino e a pesquisa". (Brasil, 2018)

Estruturando-a da seguinte forma:

"Art. $5^{\circ}$ Estruturam a concepção e a prática das Diretrizes da Extensão na Educação Superior: I - a interação dialógica da comunidade acadêmica com a sociedade por meio da troca de conhecimentos, da participação e do contato com as questões complexas contemporâneas presentes no contexto social; II - a formação cidadã dos estudantes, marcada e constituída pela vivência dos seus conhecimentos, que, de modo interprofissional e interdisciplinar, seja valorizada e integrada à matriz curricular; III - a produção de mudanças na própria instituição superior e nos demais setores da sociedade, a partir da construção e aplicação de conhecimentos, bem como por outras atividades acadêmicas e sociais; IV - a articulação entre ensino/extensão/pesquisa, ancorada em processo pedagógico único, interdisciplinar, político educacional, cultural, científico e tecnológico”. (Brasil, 2018)

Observamos que a legislação brasileira traz para a extensão universitária a interação dialética com a sociedade e a problematização de questões complexas que estão no contexto social. Além disso, espera-se que a extensão propicie uma formação cidadã aos estudantes, trazendo mudanças para sociedade e para própria universidade. Portanto, vemos que o desenvolvimento da extensão universitária no campo da educação em Direitos Humanos pode ser uma estratégia eficaz no que se refere à possibilidade da universidade desenvolver atividades que possam somar no alcance do despertar de consciência e o avanço de processos coletivos, na medida em que,

"A educação em Direitos Humanos incumbe-se, desta feita, do papel de transformadora das pedagogias educativas e da sociedade, se mostrando como uma prática social e política emancipatória, promovedora de conquistas e da proteção de direitos, capaz de formar sujeitos que exercitam a indignação frente às injustiças e desigualdades sociais e que são comprometidos com a valorização da vida em toda sua plenitude". (Almeida e Reis, 2018, p. 49)

Avaliamos que, via de regra, a concepção que se tem acerca da educação em Direitos Humanos se assenta em uma visão romantizada, trazendo a impressão de que o simples fato de se conhecer os direitos se garantirá o acesso aos mesmos. Esse elemento é delicado, pois, como refletimos acima, a positivação dos direitos não garante sua execução. Todavia, como também já abordamos, os direitos tornam-se instrumentos para luta, por isso, acreditamos que, por mais limites que se encontre, a educação em direitos humanos pode somar em processos mais amplos. 


\section{Dialogando com Gramsci sobre sujeitos singulares e coletivos: experiência do Projeto "Aproxima-Ação"}

Defendemos que os conceitos gramscianos são essencialmente atuais para o fortalecimento de caminhos capazes de se situarem na contramão de movimentos reacionários e da manutenção dos mecanismos de opressão, mostrando-se como importante referencial teórico para o diálogo entre a tradição marxista e a analise da realidade a partir das categorias classe, raça/etnia e gênero. Também consideramos como elemento importante o fato do pensador ter desenvolvido sua produção teórica em um contexto de perseguição, determinada pelo fascismo na Itália do início do século XX, sentindo, inclusive, em seu corpo e sua mente a materialidade da opressão a partir das grades do cárcere.

Além disso, a concepção gramsciana de que os sujeitos são primeiro sujeitos individuais e singulares, para posteriormente, perceberem-se como sujeitos coletivos é, a nosso ver, a forma mais interessante para a compreensão do potencial transformador humano. Justamente por conta dessas particularidades que encontramos potencial teórico capaz de colaborar para o desenvolvimento de ações de extensão universitária, as quais serão socializadas a partir da experiência da execução do Projeto de Extensão "Aproxima-Ação". A experiência será relatada a partir de um diálogo com conceitos gramscianos, utilizando basicamente três partes dos Cadernos do Cárcere, as publicações brasileiras intituladas como "Concepção Dialética da História"; "Os intelectuais e a Organização da Cultura"; "Maquiavel, a Política e o Estado Moderno". No bojo das reflexões inserimos dois poemas do formato slam poetry ${ }^{5}$ de autoria de mulheres envolvidas com a luta popular e coletiva, Mel Duarte e Roberta Estrela D'Alva.

\section{Do sujeito singular ao sujeito coletivo}

É essencial, para o presente debate, a percepção de que o homem6 pode "se tornar", pois ao considerar a singularidade humana, o pensador propõe que o homem é processo dos próprios atos. Ensina-nos também que a natureza humana é o conjunto das relações sociais, incluindo assim a ideia da possibilidade do devenir, da mudança, da transformação, afirmando que "o homem 'devém', transforma-se continuamente com as transformações das relações sociais" (Gramsci, 1984, p. 49), e ao responder a pergunta: "o que é o homem?", aponta que:

"a definição pode ser encontrada no próprio homem singular, pode-se encontrar o que é cada 'homem singular'. Mas não nos interessa o que é cada homem singular, problema que significa, ademais, o que é cada homem singular em cada momento singular. Se observarmos bem, veremos que - ao colocarmos a pergunta 'o que é o homem' - queremos dizer: o que o homem pode se tornar, isto é, se o homem pode controlar seu próprio

5) "Por mais que a poesia slam esteja se popularizando no Brasil agora, lá nos Estados Unidos tudo começou mais ou menos nos anos 1980, sob influência do movimento de verso livre - o que nós conhecemos como rap hoje em dia. Foi mais ou menos nessa época que Mark Kelly Smith, um poeta de Chicago, criou o slam. Ele achava que a poesia acadêmica era muito elitizada e queria pensar numa forma mais relaxada e livre de fazer poesia. Juntando isso com as sessões de microfone aberto para os artistas que já rolavam nos cafés por lá, esse estilo de performar as poesias surgiu. Em 1990 ele organizou a primeira competição nacional de slam e ela tem edições até hoje nos Estados Unidos". (Borges, s/f)

6) Recorrentemente a expressão homem aparecerá no sentido genérico de ser humano, envolvendo homens e mulheres 
destino, se ele pode 'se fazer', se ele pode criar sua própria vida. Digamos, portanto, que o homem é um processo, precisamente o processo de seus atos". (p. 38)

Além disso, Gramsci dispensa grande importância à cultura, pois para ele, esta é um instrumento unificador do homem coletivo, um canal que possibilita afinidades e, em meio do protagonismo humano, interfere nas relações, sendo, portanto, construída historicamente. Ridenti (1994) ressalta que a existência de uma classe não se explica somente a partir da vinculação aos processos produtivos, importando como esses sujeitos constroem a própria consciência, portanto a cultura popular, muitas vezes renegada por visões mais ortodoxas sobre processos revolucionários, é importante instrumento de resistência. $\mathrm{O}$ autor ressalta que essa consciência:

"não pode ser literalmente trazida 'de fora' da classe em si, por partidos, ou intelectuais que supostamente tenham o domínio das leis e da história, ela deve brotar dentro da própria classe, de sua práxis". (p. 24)

A cultura popular fortalece sentimentos coletivos, ancestralidade, força e solidariedade. Em âmbito urbano, destacamos o Movimento Hip Hop como expressão de cultura e resistência juvenil (Rocha, 2000), o qual, desde a década de 1980, tem representado os jovens pobres e negros, residentes em regiões espoliadas ao acesso aos Direitos Humanos em suas diferentes frentes. $\mathrm{E}$, a atualmente destacamos especialmente a realização de saraus e da prática da slam poetry, que é uma forma de expressão linguística que tem se popularizado no Brasil e estimula reflexões que tangenciam lutas e resistências que estão na esfera das questões de classe, gênero e raça. Podemos observar um pouco da proposta na poesia abaixo:

Quando o corpo fala como a voz ecoa

Quando você cala, como isso ressoa?

Onde vibra o timbre? O que te impulsiona?

O que te faz sentir livre? E o que te aprisiona?

Querer viver da nossa arte é mais que resistência

Ser representante dos seus sonhos, saber usar a sapiência

É mais que entretenimento ou distração para o momento

Nossos corpos são ato político e isso causa estranhamento

Ser cria de rua, underground

Seja na rima ou no passinho fazer da rua o seu playground

E nesse asfalto, onde alguns se arrastam

Outros erguem palco, montam a sua lona

Periferia é a arte que respira para além de ser poeta e ser a própria poesia

Eu tô falando de deslocamento, da voz ao movimento

Sair do lugar comum, explorar novos conceitos

Escurecendo os argumentos é mais que floow, é ter talento

Eu tô falando da verdade que pulsa no peito

(...) 
E sobreviver é muita treta para quem não vem de área nobre

Demarcando nosso território

A quebrada também tem repertório

(...)

Das batalhas de rima até levar o slam pro palanque

O corpo que vibra se manifesta é atuante

Para que minha geração sobreviva a esse massacre constante

Retomar o que é nosso por direito

Por mais espaços públicos para o povo periférico

Que nossa dança ressoe em corpos presos por preconceitos

Que nossa palavra atravesse barreiras e no peito cause efeito

Que nosso som extravase e chegue nos ouvidos mais primitivos

Que nossa imagem sobreponha tudo o que antes foi aprendido

E que de uma vez por todas reconheçam as nossas artes

Com o valor merecido

(Mel Duarte)

Poema que situa lugar cultura como ação crítica, "arte e resistência", fala de um cotidiano determinado por opressões, a partir de uma perspectiva orgânica, de dentro para fora, que envolve dialeticamente três momentos: vivência individual, denúncia singular e compartilhamento para coletivo. Como anuncia Mel Duarte, há possibilidades de ações reivindicatórias e resistência, pois "os corpos são ato político" e é preciso "retomar o que é nosso por direito". Foi essa compreensão que subsidiou o desenvolvimento de extensão universitária, pois se é o homem que pode se tornar e fazer história, é possível, de acordo com o grau de definição de objetivos e de consciência crítica, que a educação possa se tornar instrumento de resistência.

O Projeto de Extensão "Aproxima-Ação", situado no campo da educação em Direitos Humanos, se justificou a partir do respeito às vivências cotidianas e a ampliação de consciência crítica acerca da realidade social. Na tríade de sujeitos que a extensão universitária envolve - docentes, estudantes, comunidade -, o primeiro movimento de construção de consciência coletiva se deu na formação dos próprios estudantes envolvidos no projeto. Gramsci caracteriza o sujeito social como resultado de um processo, respeitando a individualidade e mostrando que é por meio desta que se constrói o coletivo:

"em suma, deve-se conceber o homem como uma série de relações ativas (um processo), no qual, se a individualidade tem a máxima importância, não é todavia o único elemento a ser considerado. A humanidade que se reflete em cada individualidade é composta de diversos elementos: 1) o indivíduo; 2) os outros homens; 3) a natureza. Mas o segundo e o terceiro elementos não são tão simples quanto poderia parecer. $O$ indivíduo não entra em relação com os outros homens por justaposição, mas organicamente, isto é, na medida em que passa a fazer parte de organismos, dos mais simples aos mais complexos". (p. 39) 
Ou seja, consciência individual sobre si próprio e do lugar que se ocupa no coletivo é essencial. Neste contexto se dá a importância da desconstrução de discursos que perpetuam o patriarcado, o racismo e a exploração. Ao longo de quatro anos de execução do projeto, estudantes bolsistas ou sem bolsa, empenharam-se na busca de conhecimentos acerca dos Direitos Humanos em uma perspectiva de romperem com resquícios de posicionamentos cunhados em visões equivocadas sobre esses direitos. No bojo deste processo também se situou a questão da própria identidade racial e de gênero, reflexões doloridas sobre lugar de fala e, principalmente, sobre a violência do racismo e machismo que foram vítimas ou reproduziram. Perguntas que nortearam o processo de formação dos estudantes: como defender os Direitos Humanos se eu mesmo não tenho certeza se os defendo? Como combater o racismo e o machismo se eu mesmo não quero tocar nestes assuntos por conta de minhas feridas? Como combater o racismo e o machismo se tenho dúvidas se essas formas de violência são reais? Este processo reflexivo com estudantes que passaram pelo projeto foi uma constante tarefa das docentes envolvidas e, é claro, dessas consigo mesmas.

É no processo de troca que a consciência coletiva se constrói e se fortalece, como Gramsci (p. 40) afirma ao discutir a relação do homem com a natureza (que envolve trabalho e técnica), é possível que "cada um transforma a si mesmo, se modifica, na medida em que transforma e modifica todo o conjunto de relações do qual ele é o ponto central". Exemplifica, que neste sentido, é o homem ativo o modificador do ambiente, ou seja, o conjunto de relações que faz parte, afirmando ainda que "se a própria individualidade é o conjunto destas relações, conquistar uma personalidade significa adquirir consciência de tais relações, modificar a própria personalidade significa modificar o conjunto de tais relações" (p. 40). A nosso ver, a reflexão gramsciana transcende as relações de trabalho envolvendo aspectos que se situam na esfera da consciência mediante as diferentes formas de opressões. $E$, desta forma, vinculamos ao debate de Paulo Freire (1979), quando enfatiza a importância da "conscientização", pois:

"Aqueles que estão 'conscientizados' apoderam-se de sua própria situação, inserem-se nela para transformá-la, ao menos com seu projeto e com seus esforços. Portanto, a conscientização não pode pretender nenhuma 'neutralidade'. Como consequência que é da educação, demonstra que esta também não poderia ser neutra, porque se apresenta sempre, queiramos ou não, como 'a forma própria de uma ação do homem sobre o mundo'”. (p. 40)

Portanto, o educador propõe a valorização dos conhecimentos cotidianos e populares, acreditando que um dos instrumentos para o alcance da transformação pode ser atribuído à promoção de novas maneiras de pensar, ampliando-se assim a consciência, visando à organização para se efetivar a luta do coletivo, como nos convida a poesia:

Se tentarem te derrubar, não deixa. Não deixa

(...)

E suportar a pressão é trabalho de herói

Mas se Zumbi somos nós, não é mais pessoal

Então... Falar é fácil. Eu sei. Isso não é sermão

Que a escolha encolha, se não tem opção 
Que o caminho bifurca e turva a visão

Mas o guia tá no peito e se chama coração

Junta todo mundo pra somar

E não tem mais eu, eles, vocês

Agora é nós, porque é só junto que combate a estupidez

Bota a boca no mundo contra o desamparo e a escassez

Vai pra rua, vai pra pista

(...)

É muita ideia que vem, mas precisamos colocar em prática

Além de grana, precisamos de gana

Estratégia e tática

Pois ainda ninguém encontrou a fórmula mágica

É preciso desapegar do passado

Virar o disco

Virar a página

Superar o sistema binário

Ampliar o vocabulário

Plasmar vitória na maior disputa

Que é pelo imaginário

Nova luz, novos atores, novo diretor, novo cenário

(...)

(Roberta Estrela D'alva)

Este poema faz um apelo ao coletivo, após a consciência singular, só o coletivo é capaz de encaminhar conquistas, pois "se Zumbi ${ }^{7}$ somos nós, não é mais pessoal" e "junta todo mundo pra somar, e não tem mais eu, eles vocês. Agora é nós, porque é só junto que combate a estupidez". Exatamente o que fala Gramsci, quando nos ensina que o primeiro determinante para a conquista do sujeito crítico, é que este reconheça a própria historicidade. E este debate acerca do posicionamento político coletivo se justifica ao pensarmos na extensão universitária como instrumento social, que pode ir para as comunidades mais afastadas em uma perspectiva de tecer aproximações entre a população historicamente excluída da própria universidade e de outros direitos. Obstante a este entendimento, nosso primeiro passo foi a realização de oficinas em Londrina e região, ${ }^{8}$ as quais aconteceram em diferentes instituições e locais, dentre elas escolas, comunidades terapêuticas, CRAS Centro de Referência da Assistência Social, ${ }^{9}$ CREAS - Centro de Referência Especializado

7) Zumbi é um herói negro brasileiro, líder do Quilombo dos Palmares 8) Realizamos essa frente antes mesmo da chegada do recurso financeiro

9) CRAS é o Centro de Referência da Assistência Social. É uma unidade pública da Assistência Social que oferece atendimentos individualizados (ou em grupos) a indivíduos e famílias. Nestes atendimentos, as pessoas podem compartilhar questões diversas relativas ao seu dia-a-dia em família e na comunidade, a exemplo das suas dificuldades de relacionamento, de sobrevivência, dos cuidados com os filhos e até situações mais delicadas como violência doméstica (Brasil, 2020b). 
de Assistência Social, ${ }^{10}$ CAPS - Centros de Atenção Psicossocial,,${ }^{11}$ Centro de Convivência e Fortalecimento de Vínculos, ${ }^{12}$ entre outros. Além disso, executamos um subprojeto nomeado como Cine-Multiplica, que promovia a exibição de filmes que debatiam a questão dos Direitos Humanos. Seguimos, em linhas gerais a metodologia de Paulo Freire, entendendo que:

"O método gera um processo de mudança e termina por identificar-se com ele, posto que a pedagogia coincide com um estilo muito exato de prática social, o da tomada de consciência, ou melhor, o da conscientização. Certamente, esta objetivação - condicionada pela posição que o indivíduo ocupa na sociedade - pode alcançar diferentes níveis: a superação de uma atitude mágica dá, gradualmente, primeiro uma opinião vaga - freqüentemente tomada de outrem, depois uma apreensão não crítica dos fatos e, enfim, no caso da conscientização, uma captação correta e crítica dos verdadeiros mecanismos dos fenômenos naturais ou humanos Mas qualquer que seja o grau a que chegue, esta superação procura sempre uma apropriação da conjuntura por parte de seus atores". (p. 40)

Neste sentido os processos formativos buscam o aprofundamento de questões acerca de opressões que grupos e segmentos sociais estão submetidos e outros debates que podem auxiliar na construção da consciência crítica e multiplicadora. Acreditamos que qualquer processo que pretende atuar na esfera de uma educação crítica precisa de aprofundamento capaz de empoderar teórica e metodologicamente seus agentes mediadores. Entendemos o empoderamento a partir das sínteses ${ }^{13}$ desenvolvidas por Joice Berth (2019) ao se referir que:

"Empoderar, dentro das premissas sugeridas, é, antes de tudo, pensar em caminhos de reconstrução das bases sociopolíticas, rompendo concomitantemente com o que está posto, entendendo ser esta formação de todas as vertentes opressoras que temos visto ao longo da História. Esse entendimento é um dos escudos mais eficientes no combate à banalização e ao esvaziamento de toda a teoria construída e de sua aplicação como instrumento de transformação social”. (p. 23)

10) O Centro de Referência Especializado de Assistência Social é uma unidade pública da Assistência Social que atende pessoas que vivenciam situações de violações de direitos ou de violências. Uma pessoa será atendida no CREAS, entre outras situações, por sofrer algum tipo de assédio, de discriminação, de abuso, de violência ou por demandar cuidados em razão da idade ou deficiência (Brasil, 2020b).

11) Os Centros de Atenção Psicossocial (CAPS) nas suas diferentes modalidades são pontos de atenção estratégicos da RAPS: serviços de saúde de caráter aberto e comunitário constituído por equipe multiprofissional e que atua sobre a ótica interdisciplinar e realiza prioritariamente atendimento às pessoas com sofrimento ou transtorno mental, incluindo aquelas com necessidades decorrentes do uso de álcool e outras drogas, em sua área territorial, seja em situações de crise ou nos processos de reabilitação psicossocial e são substitutivos ao modelo asilar (Brasil, 2020c). 12) O SCFV é um serviço da Proteção Social Básica do SUAS que é ofertado de forma complementar ao trabalho social com famílias realizado por meio do Serviço de Proteção e Atendimento Integral às Famílias (PAIF) e do Serviço de Proteção e Atendimento Especializado às Famílias e Indivíduos (PAEFI). O Serviço de Convivência e Fortalecimento de Vínculos (SCFV) realiza atendimentos em grupo. São atividades artísticas, culturais, de lazer e esportivas, dentre outras, de acordo com a idade dos usuários. É uma forma de intervenção social planejada que cria situações desafiadoras, estimula e orienta os usuários na construção e reconstrução de suas histórias e vivências individuais, coletivas e familiares (Brasil, 2020).

13) Cunhada pelos debates empreendidos por Hannah Arendt, Foucault, Patrícia Hill Collins, Barbara Bryan Solomon, Cecília Sardenberg, Rute Baquero, Paulo Freire entre outros. 
Acreditamos no empoderamento que se situa dialeticamente no movimento entre singular, particular e universal/coletivo. Portanto, no caso da extensão universitária, o empoderamento deve ser o instrumento mediador que irá potencializar trocas dialógicas entre todos os protagonistas, sejam docentes, estudantes, profissionais, comunidade, jovens e adolescentes, defensores de direitos, ativistas, conselheiros de direitos, etc. a partir da construção de atividades de extensão. Como sabemos não é possível atribuir papel revolucionário à educação isoladamente, entretanto, defendemos que esta pode ser utilizada como instrumento organizacional da classe oprimida, sendo inclusive, essencial o envolvimento dos intelectuais orgânicos representantes desta.

Convém destacarmos que foi a partir da realização das oficinas que a docente coordenadora inaugurou suas ações com atividades extensionistas demarcando um posicionamento compromissado mediante as três frentes do tripé ensino, pesquisa e extensão que compõe a universidade pública, gratuita e de qualidade. Avaliamos que a experiência foi muito interessante para docentes envolvidas, estudantes e comunidade, à medida que as atividades aconteceram de maneira coletiva, visando o planejamento de ações em grupo, avaliações e reconstruções de propostas. Ao programarmos a realização de oficinas, sempre nos pautamos em uma metodologia capaz de mesclar as categorias que compõe a práxis: singularidade, particularidade e universalidade. Priorizávamos uma linguagem de fácil acesso, que sempre estimulou o envolvimento da comunidade, buscando que os participantes se colocassem como sujeitos que já possuem entendimento sobre temas abordados. Esse entendimento prévio, por sua vez, sempre foi valorizado como importante e essencial, a partir da aí, os debates propunham ampliação de conhecimento para todos os envolvidos, ou seja, os sujeitos que coordenavam as oficinas - estudantes e docentes - sempre aprendiam com os sujeitos da comunidade, fazendo que a aproximação se tornasse ação.

\section{Universidade no contexto da contra-hegemonia}

É essencial a compreensão do movimento entre hegemonia/contra-hegemonia, para isso, consideramos que ideologia e cultura estão relacionadas. Vemos elementos geradores de processos no fato de falarmos sobre direitos humanos e tudo que os envolve, estimulando a população a fortalecer seu potencial de resistência e reinvindicação, e é neste sentido que refletiremos sobre o papel da universidade sob a luz do pensamento gramsciano. Visualizamos que um dos grandes legados de Gramsci, está na defesa da possibilidade da construção de uma "nova cultura":

"Criar uma nova cultura não significa apenas fazer individualmente descobertas 'originais'; significa também, e sobretudo, difundir criticamente verdade já descobertas, 'socializá -las' por assim dizer; transformá-las, portanto, em base de ações vitais, em elemento de coordenação e de ordem intelectual e moral. $O$ fato de que uma multidão de homens seja conduzida a pensar coerentemente e de maneira unitária a realidade presente é um fato 'filosófico' bem mais importante e 'original' do que a descoberta, por parte de uma 'gênio filosófico', de uma nova verdade que permaneça como patrimônio de pequenos grupos intelectuais". (1981, pp. 13-14)

A responsabilidade da construção de uma nova cultura também é da universidade, na medida em que de nada adianta descobertas que permaneçam nas mãos de poucos, que 
não sirvam para mudanças efetivas na sociedade. Essencial é que o tripé ensino, pesquisa e extensão aconteça em nome de uma sociedade que os Direitos Humanos sejam respeitados e efetivados. Por isso nos interessa também o papel que Gramsci atribui às "concepções de mundo", que podemos relacionar à reprodução ideológica, pois, segundo ele, são impostas por grupos sociais dominantes. Para efetivação da ideologia político-econômica da classe dominante, utilizam-se de concepções alienantes que mantém a hegemonia do capital. O que nos cabe, neste momento, é perceber que a disputa se coloca no contexto contraditório entre a manutenção da hegemonia dominante e o desenvolvimento de papel contra-hegemônico.

As instituições escolares estão inseridas na esfera da superestrutura, as quais representam o conjunto de ideias, valores, costumes e comportamentos morais. E, dentro de uma reflexão mais ampla, entendemos as instituições escolares como a materialização da educação formal, por isso inserimos a universidade neste contexto, pois, historicamente tem sido território elitizado e de privilégios, que só foi submetida a pequenas mudanças após a conquista de movimentos que pautavam direitos civis e políticas afirmativas. Consideramos que para além das áreas de humanas e ciências sociais aplicadas, a universidade está imbuída de influências ídeo-políticas, pois mesmo na área de exatas, biológicas, ciências da saúde, etc., o debate acerca da responsabilidade social do processo formativo deveria subsidiar o compromisso pós-universidade. Essa reflexão se centra no fato de que Gramsci (1984, p. 37) nos ensina que a metodologia desenvolvida para a "transmissão" da educação não é neutra, pois sempre existe um cunho ideológico que o norteia e direciona para a manutenção hegemônica de determinados grupos. E, quando o processo formativo universitário serve mais para manutenção da divisão de classes ou do acúmulo de capital, só fortalece as relações sociais estabelecidas no capitalismo, ou seja, a educação conduzida pelo Estado burguês, torna-se aparelho hegemônico na manutenção de desigualdades.

Em meio aos conflitos sociais, Gramsci (1978) ressalta que a "escola desenvolve função educativa positiva, e os tribunais, como função educativa repressiva e negativa", considerando-as como as mais importantes atividades do Estado, afirma ainda que ambos possuem o mesmo objetivo real, pois "tendem para este fim uma multiplicidade de outras iniciativas e de outras atividades ditas privadas que formam o aparelho da hegemonia política e cultural das classes dominantes" (p. 231).

No entanto, o movimento dialético nos permite acreditar no oposto, no revés que se materializa no potencial contra-hegemônico da educação, pois ao mesmo tempo que se reproduzem ideologias dominantes, poderá, transmitir ideologias que nascem pela libertação da classe oprimida, podendo ser, desta forma, utilizada como instrumento para a busca do despertar de consciência, e é desta forma que entendemos o desenvolvimento de ações de extensão universitária, especialmente quando se trata da educação em Direitos Humanos. A participação discente contou com 8 bolsistas de diferentes áreas, dentre elas, Serviço Social, Psicologia, Artes Cênicas, Direito, Designer, Relações Públicas. O envolvimento das(os) estudantes foi intensa, o que possibilitou experiência ímpar no processo de assessoramento da construção das propostas, levantamento dos materiais necessários e acompanhamento da execução em diferentes territórios e regiões, permitindo o envolvimento direto com a realidade. Além disso, mostraram-se sempre empenhadas(os) em estudar, pesquisar, debater e construir coletivamente, pois, as relações pedagógicas devem acontecer de forma dialética, 
"segundo as quais a relação entre professor e aluno é uma relação ativa, de vinculações recíprocas, e que, portanto, todo professor é sempre aluno e todo aluno, professor" (Gramsci, 1984, p. 37) e, no caso da extensão, inserimos as pessoas que terão acesso às atividades da extensão universitária dentro desta trilogia de sujeitos: estudantes, docentes e comunidade.

Foi a partir destes pressupostos que construímos a proposta do Curso "Multiplicando os Direitos Humanos e o ECA" em consonância com o Plano Nacional de Direitos Humanos - PNDH-3 (Brasil, 2009), que dentre suas linhas de atuação coloca a Educação em Direitos Humanos:

"como canal estratégico capaz de produzir uma sociedade igualitária, extrapola o direito à educação permanente e de qualidade. Trata-se de mecanismo que articula, entre outros elementos: a) a apreensão de conhecimentos historicamente construídos sobre Direitos Humanos e a sua relação com os contextos internacional, nacional, regional e local; b) a afirmação de valores, atitudes e práticas sociais que expressem a cultura dos Direitos Humanos em todos os espaços da sociedade; c) a formação de consciência cidadã capaz de se fazer presente nos níveis cognitivo, social, ético e político; d) o desenvolvimento de processos metodológicos participativos e de construção coletiva, utilizando linguagens e materiais didáticos contextualizados; e) o fortalecimento de políticas que gerem ações e instrumentos em favor da promoção, da proteção e da defesa dos Direitos Humanos, bem como da reparação das violações". (Brasil, 2009)

Elementos esses que foram os princípios norteadores para o planejamento das aulas/ oficinas, portanto, o curso teve como objetivo formar multiplicadores e defensores dos Direitos Humanos e do ECA, por isso, voltou-se para pessoas que já desenvolviam alguma atividade coletiva (educadores, profissionais, lideranças comunitárias, conselheiros de direitos, representantes de movimentos, membros de ONG's, equipe técnica, entre outros). O edital de seleção foi construído coletivamente e optamos por prezar o potencial multiplicador dos interessados, portanto não foi exigida escolaridade, apenas o comprovante de representatividade social e coletiva. Para a divulgação, docentes e bolsistas visitaram instituições, organizações sociais, movimentos, Secretaria Estadual de Educação, entre outros locais. Além disso, realizamos intensa divulgação por email e redes sociais. Neste sentido, a turma de cursistas foi bem diversa, envolvendo educadores, ativistas, estudantes, assistentes sociais, psicólogas, conselheiras tutelares, terapeuta ocupacional, donas de casa com atuações nas comunidades, entre outros.

O curso aconteceu no formato presencial, com aulas presenciais nas dependências da UEL - Universidade Estadual de Londrina e foi dividido em três momentos: a) Aproximação teórica que consistiu em 32 horas teóricas; b) Multiplicação Prática de 16 horas; c) Disseminação dos resultados a partir de evento para a socialização das experiências dos cursistas. As aulas foram ministradas pelas coordenadoras e por colegas educadores e docentes, que colaboraram com o projeto de maneira solidária, sem recebimento de pró-labore. O currículo do curso abordou os temas: Direitos Humanos, expressões e Violações; Histórico da Política de Atendimento à Criança e Adolescente no Brasil e sua consolidação; Realidade do Jovem e do adolescente brasileiro; Igualdade Racial e combate ao racismo; Gênero e respeito à diversidade; Uso abusivo de álcool e outras drogas e a redução de danos; Protagonismo, Educação Popular e Teatro do Oprimido; Comunicação Popular e a Defesa dos Direitos Humanos. 
O conteúdo abordado tratou a transversalidade dos Direitos Humanos e propôs um debate na esfera de reflexões histórico-críticas, capaz de somar na ampliação de saberes e, como temos dito, possibilitar a consciência crítica singular e coletiva. Acreditamos que dessa forma, a partir dessa pequena experiência, fortalecemos nuances contra-hegemônicas na esfera da universidade. E isso não se mostrou apenas para a comunidade, mas para todos os sujeitos envolvidos - docentes, estudantes e comunidade. Destacamos que no interior das reflexões, buscávamos estimular os cursistas a empreenderem atividades geradoras de processos em suas bases coletivas e a ocuparem lugar nos Conselhos de Direitos, que são instâncias democráticas conquistadas no processo de redemocratização do país, buscando desta forma, que os participantes, pudessem encontrar maneiras para a construção coletiva em ações cotidianas.

Destacamos que em "Maquiavel, a Política e o Estado Moderno", Gramsci (1991, p. 39), ao fazer uma crítica ao economicismo, mostra que a hegemonia se constrói a partir da "a análise dos diversos graus de relação de forças só pode culminar na esfera da hegemonia e das relações ético-políticas", tendo como fundamento teórico-metodológico a filosofia da práxis. De forma dialética, mostra que o movimento pela conquista do poder nas relações ético-políticas, definem o âmbito econômico, como podemos perceber na citação abaixo:

"o fato da hegemonia pressupõe indubitavelmente que se deve levar em conta os interesses e as tendências dos grupos sobre os quais a hegemonia será exercida, que se forme certo equilíbrio de compromisso, isto é, que o grupo dirigente faça sacrifícios de ordem econômico-corporativa. Mas também é indubitável que os sacrifícios e o compromisso não se relacionam com o essencial pois se a hegemonia é ético-política também é econômica, não pode deixar de se fundamentar na função decisiva que o grupo dirigente exerce no núcleo decisivo da atividade econômica". (p. 33).

Essencial compreendermos que para Gramsci a luta pela conquista hegemônica se faz por meio da disputa de grupos pertencentes a "blocos" construídos historicamente, formados no bojo da relação dialética entre estrutura e superestrutura, afirmando que as superestruturas são reflexos da estrutura (relações sociais de produção). Esta compreensão da dialética entre estrutura e superestrutura se dão no bojo do movimento pela luta na conquista (ou imposição) de hegemonia, em meio de tensões materializadas nas "relações de força", que acontecem em três momentos fundamentais.

O primeiro se refere à estrutura material e aos meios de produção, relações concretas ligadas "à estrutura, objetiva, independente da vontade dos homens. (...) À base do grau de desenvolvimento das forças materiais de produção"(1991, p. 49), as quais, por sua vez, determinam as construções ideológicas. A problematização deste momento das relações de força é essencial, pois sociabilidade do capital se estabelece a partir das relações de produção, e essas, se centram na exploração da força de trabalho e acúmulo de capital. Em nossa experiência com realização do curso, esses debates sempre se deram transversalmente e a partir das vivencias dos próprios participantes acerca da questão do trabalho, da exploração, do desemprego e outros elementos vinculados à questão estrutural, sempre abordando as contradições próprias do modo de produção capitalista.

Gramsci define que o segundo momento acontece no âmbito da consciência, estando, desta forma, inserido no contexto da superestrutura mostrando-se a partir da "relação de 
forças políticas" caracterizada como um momento de avaliação do grau da organização, de homogeneidade e autoconsciência de grupos sociais, "por sua vez, este momento pode ser analisado e diferenciado em vários graus, que correspondem aos diversos momentos da consciência política coletiva, da forma como se manifestaram na história até agora" (p. 49).

Neste sentido sempre conduzimos reflexões sobre o papel que os sistemas de opressão desempenham para a manutenção da sociabilidade burguesa, ou seja, o quanto as questões de classe, racial e de gênero, promovem desigualdades e favorecem as forças produtivas e acúmulo de capital. É em uma sociedade impetrada por diferentes contradições que os sujeitos tendem a construir posicionamentos contestatórios que podem se materializar a partir da participação em movimentos sociais organizados ou de movimentos espontâneos os quais se mostram de diferentes maneiras. Como conceitua Gohn (1997):

"Movimentos sociais são fenômenos históricos, decorrentes de lutas sociais. Colocam atores específicos sob as luzes da ribalta em períodos determinados. Com as mudanças estruturais e conjunturais da sociedade civil e política, eles se transformam. Enquanto a sociedade não resolver seus problemas básicos de desigualdades sociais, opressão e exclusão, haverá lutas, haverá movimentos. E deverá haver teorias para explicá-los”. (pp. 19-20)

No Brasil, um grande exemplo de relação de forças políticas se mostra na luta dos movimentos sociais nas décadas de 1970 e 1980 pelo fim da ordem ditatorial e no interior do processo de construção da Constituição de 1988. A carta magna brasileira foi resultado de lutas por direitos civis, políticos, sociais, econômicos e culturais, nas quais os movimentos sociais conquistaram a garantia dos direitos humanos e universais, como também se estabeleceram mecanismos de controle social pela via de Conselhos democráticos e paritários. Destaque também deve ser dado à conquista do Estatuto da Criança e do Adolescente de 1990, que demarca no Brasil a doutrina da proteção integral e entende crianças e adolescentes como pessoas em processo de desenvolvimento, a partir da concepção dos direitos humanos voltados ao público infanto-juvenil. Na sequência vieram outras legislações de proteção a grupos específicos, a exemplo da população negra, pessoa com deficiência, idosos, entre outros, todas com respaldo legal na constituição.

No entanto, como demonstra Gramsci, no bojo da "relação de forças políticas" se situam tensões, portanto o processo de constituinte não esteve imune a isso, haja visto que a Constituição de 1988 foi promulgada, segundo Evelina Dagnino (2004), em um contexto de disputa entre dois projetos político-econômicos para o país, um de reconstrução democrática e garantia dos direitos sociais, outro de adesão à onda neoliberal que vinha sendo implantada mundialmente a partir de meados da década de 1980. Por isso, a carta magna brasileira apresenta-se como um híbrido de garantia cidadã e fortalecimento da rede privada,14 trazendo uma confluência perversa.

De qualquer forma, sempre consideramos a positivação dos direitos como parte da concretização de lutas, que se estendem para proteção e efetivação, portanto, as atividades do

14) Como exemplo podemos mencionar os principais direitos universais presentes na carta magna: saúde e educação. Pois mesmo havendo a universalidade desses direitos, a lei dedica grandes espaços para o fortalecimento da saúde e educação privada o que, em momentos de agravamento da crise capitalista, faz com que o privatismo cresça em detrimento do garantismo de direitos. 
projeto de extensão sempre buscaram apresentar os direitos humanos aos participantes. Além disso, vemos que um dos grandes legados das lutas sociais brasileiras foi o controle social pela via da democracia participativa, por meio dos Conselhos de Direitos, os quais vêm sendo desmontados de forma frontal. Neste sentido, sempre estimulamos os sujeitos a conhecerem os conselhos, estimulando-os à participação em instâncias coletivas, a exemplo das conferências.

Há ainda o terceiro momento das relações de forças, as quais, Gramsci (1991) situa na esfera da "relação de forças militares" divididas nos graus técnico-militar e político militar, que servem para manter o domínio hegemônico de nações sobre nações ${ }^{15}$. Para ele essa esfera é decisiva e o desenvolvimento histórico oscila entre o primeiro e o terceiro momento com a mediação do segundo. Refletimos aqui, que o Estado se utiliza da força militar (técnica ou política) quando não há hegemonia através do consenso, podendo desta forma agir de forma ditatorial. Neste terreno também situamos o chamado Estado penal (Wacquant, 2013), que administra as mazelas da política econômica neoliberal por meio de mecanismos de controle diretos, que criminalizam os negros e pobres, controlando a questão da população excedente pela via de políticas punitivas, as quais se dão em meio aberto e também se mostram no encarceramento em massa.

Ao refletirmos sobre os três tipos de relações de força, observamos que a função social da universidade pode se efetivar quando seus membros a traduza como território contra-hegemônico, rompendo com os fundamentos elitistas e excludentes sob os quais foi construída. Quando o pensador discute o papel dos intelectuais orgânicos, aponta que a grande maioria desses é utilizada pela classe dominante, ressaltando a importância da classe proletária ter seus próprios intelectuais, "categorias especializadas para a função intelectual são formadas cotidianamente. Tais categorias estão ligadas aos diversos grupos sociais, porém na maioria das vezes estão em conexão com os grupos sociais da classe dominante" (Gramsci, 1995, pp. 8-9). Neste ponto se insere a importância de políticas afirmativas ${ }^{16}$ de acesso e permanência, as quais têm possibilitado que a educação pública universitária esteja sendo ocupada por grupos sociais que historicamente estiveram afastados da formação superior, especialmente os negros e indígenas. Acreditamos que somente com a presença dos intelectuais orgânicos da classe trabalhadora e submetida a diferentes formas de opressões que a universidade se tornará plural, diversa e comprometida socialmente.

$E$, no movimento dialético que envolve a relação dos sujeitos envolvidos com a extensão universitária observemos três elementos interessantes. O primeiro se mostra na participação de estudantes que tiveram história de vida marcada pelos mecanismos de opressão destacados acima. Esses intelectuais orgânicos se empenharam muito nas atividades de extensão a partir de um lugar de vivência e identidades. O segundo elemento se mostrou no envolvimento de estudantes provenientes de classes sociais mais abastadas, os quais nunca haviam tido contato de maneira crítico-reflexiva diante da concreticidade da pobreza, do racismo, do ma-

15) Vale ressaltarmos que Gramsci faz, inclusive a menção a relações internacionais de luta por independência, apontando que um país só poderá se tornar livre da opressão de outro, quando envolver suas forças militares.

16) E esse debate não acontece livre de tensões, pois grupos reacionários se posicionam claramente contra essas políticas, negando a dívida histórica do país com estes grupos sociais. Além disso, propagam elementos capazes de agravar racismo e exclusão social, dificultando o cotidiano de jovens cotistas em universidades públicas. 
chismo e das inúmeras outras violações dos direitos humanos. E no bojo desses elementos se constrói o terceiro, que se refere à importância e o papel educativo dos sujeitos da comunidade que se abriram para universidade, permitindo a troca mútua entre todos os envolvidos.

Destacamos que abordávamos os fenômenos a partir de diferentes lugares e pontos de vista capazes de despertar a análise crítica da realidade, fortalecendo a troca entre os sujeitos envolvidos, valorizando o potencial das reflexões singulares, individuais e o aspecto coletivo dessas vivências. Neste sentido, a participação da comunidade foi intensa e os sujeitos sempre trouxeram suas vivências, fazendo a vinculação da realidade abordada teoricamente com a realidade por eles vivenciada, demonstrando que teoria e prática estão vinculadas dialeticamente. Levando, desta forma os estudantes participantes do projeto a visualizarem que toda aquela problematização e abordagem teórica desenvolvida na universidade se refere a aspectos da vida real, do cotidiano de pessoas, de sujeitos. Ousamos dizer que a vivência na execução do Projeto Aproxima-Ação mostrou aos estudantes a necessidade de compromissos sociais no exercício de suas profissões posteriormente.

Por fim é essencial relatarmos que um dos objetivos do projeto também foi fortalecer multiplicadores, por isso, os membros da comunidade externa que participaram do curso, após concluírem as aulas teóricas, planejaram e aplicaram oficinas e/ou outras atividades em suas bases, concluindo a parte prática. Ressaltamos que as bolsistas também acompanharam a parte prática das oficinas organizadas pelos cursistas, assessorando na construção das propostas e execução das atividades, fazendo com que estivessem presentes em espaços ainda desconhecidos para algumas delas.

Enfatizamos que o projeto Aproxima-Ação envolveu suas frentes dialeticamente ${ }^{17}$ e cada uma delas trouxe subsídios para próxima etapa, neste sentido potencializamos a confecção da cartilha "Multiplicando Direitos", que foi construída pela equipe de bolsistas e docentes envolvidas, objetivando colaborar para que educadores, ativistas e multiplicadores, pudessem desenvolver debates afeitos a temática dos Direitos Humanos a partir da sua materialização em diferentes esferas das relações sociais. A cartilha teve uma tiragem de 700 exemplares, o conteúdo se pautou nos temas desenvolvidos no curso, os quais suscitaram debates interessantes e nos mostraram a linguagem que deveríamos abordar no material, fazendo a junção de um debate essencial com uma estética atrativa para despertar o interesse. O material oferece sugestões para abordagens, utilização de dinâmicas, músicas, entre outros elementos artísticos e culturais. A distribuição é gratuita e tem como foco protagonistas que poderão utilizá-las para atividades educativas e potencializadoras.

Finalizamos nosso diálogo com Gramsci destacando a importante socialização de conhecimentos, tendo como enfoque principal o ser humano em sua totalidade, sujeito coletivo,

17) Destacamos, que apesar de todos os impactos positivos, a execução do projeto não aconteceu isenta de percalços. A principal dificuldade se referiu ao fato de que a maioria dos equipamentos que seriam utilizados durante o curso, a exemplo de computadores que estariam acessível aos cursistas, geladeira para preservação dos lanches que eram comunitários para os intervalos, data show para utilização nas oficinas, etc... que foram comprados com o recurso MEC-PROEXT só chegaram depois do final do curso. Outro elemento foi que para submissão do projeto contamos no orçamento com a compra de um veículo para as atividades externas, no entanto, com o atraso da verba o valor ficou defasado, não sendo possível a compra. Por isso, as atividades externas foram realizadas com carros próprios das docentes e transporte público. Em relação à dificuldade que está na esfera dos resultados, nos deparamos com a desistência de alguns cursistas, inicialmente aceitamos 40 pessoas, porém algumas desistiram durante o processo. 
transformador e protagonista. Portanto, essencial se faz que assumamos a posição contra-hegemônica, reconhecendo qual tipo de conformismo pertencemos. Nas palavras dele:

"Somos conformistas de algum conformismo, somos sempre homens-massa ou homens coletivo. O problema é o seguinte: qual é o tipo histórico do conformismo e do homem massa do qual fazemos parte?". (1981, p. 12)

Por isso, não nos conformemos com a opressão em curso e com as intimidações que tentam nos impor. Que fundamentemos nossas atividades educativas cotidianas em debates que se situam na esfera da contra-hegemonia e possamos, dialética e historicamente, implementar debates coletivos que suscitem reflexões igualmente coletivas, pois como nos convida Conceição Evaristo:

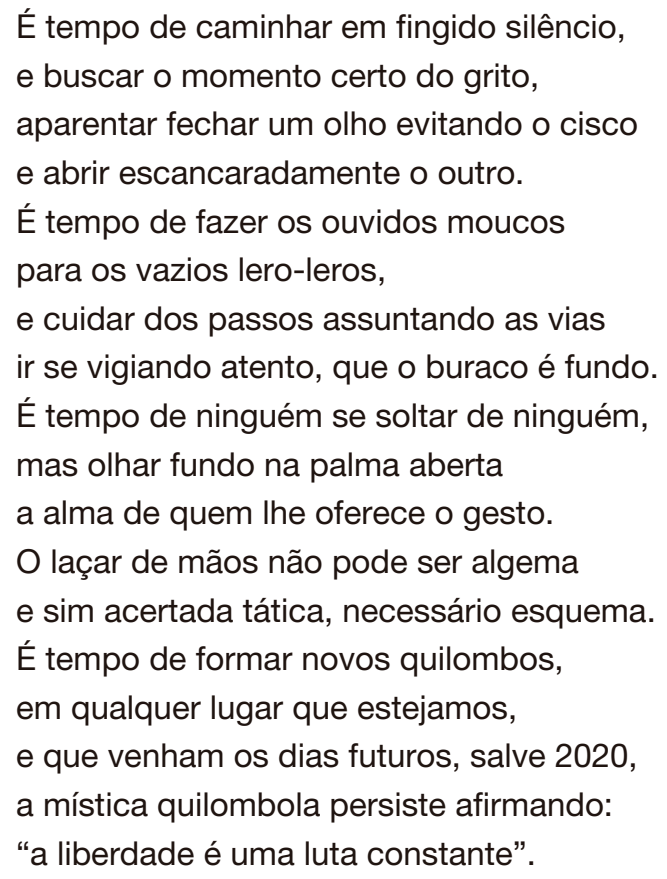

Que a universidade possa se aquilombar ${ }^{18}$ e fortalecer-se como lugar de resistência e luta contra-hegemônica. É este o caminho que temos tentado dar para as ações de extensão universitária que empreendemos, nas quais sujeitos somos todos nós.

18) Clóvis Moura (1987, p. 94), ao descontruir a história hegemônica sobre regime escravista e negros escravizados no Brasil afirma que "várias foram as formas de resistência do escravo negro ao regime escravista. Mesmo com todas as limitações que a estrutura do sistema impunha ao cativo, ele ao contrário do que afirma [afirmam] aqueles que seguem a chamada historiográfica acadêmica, resistiu de várias formas e níveis de importância durante todo o tempo em que a escravidão perdurou. Resistiu de várias formas ativas, como as insurreições citadinas até os quilombos disseminados em todo o território nacional (...) e as guerrilhas que permeavam as duas formas fundamentais de resistência", por isso, a expressão aquilombar-se tem sido utilizada como exemplo de luta e resistência. 


\section{Algumas considerações}

Tecemos reflexões assentadas em dois pressupostos que estão dialeticamente vinculados, mas ocupam polos opostos na arena da luta de classes. O primeiro diz respeito ao fato de que o modo de produção capitalista sustenta sua estrutura econômica a partir de relações superestruturais, materialmente ancoradas por mecanismos de opressão situados, especialmente, na exploração do trabalho, no racismo e no patriarcado. Mecanismos que, por sua vez, se retroalimentam e utilizam-se de discursos cunhados em uma ideologia capaz de mantê-los em reprodução. $O$ segundo pressuposto que delineou as análises deste artigo se refere ao entendimento de que a realidade está em movimento e a história é construída coletivamente, o que nos leva a defender a importância da constituição de resistências populares, as quais, sem sombra de dúvidas, somarão na construção da práxis revolucionária.

Por isso, nos centramos em elementos teóricos que colaboram no entendimento acerca do potencial transformador de homens e mulheres, os quais, segundo Gramsci, precisam reconhecerem-se primeiramente como sujeitos individuais, que possuem singularidades que os levam ao lugar de sujeitos coletivos e transformadores da história. No entanto, geralmente essa transição do reconhecimento individual para luta coletiva não acontece espontaneamente, mas depende de processos que estimulam o despertar de consciência crítica acerca das contradições da sociabilidade burguesa. Gramsci dedica grande parte de seus escritos à educação e "seu papel", demonstrando que na esfera da superestrutura pode manter-se representando a hegemonia dominante em nome da manutenção da ordem capitalista, ou tornar-se instrumento contra-hegemônico, em contraposição a essa ordem.

A educação é, portanto, um dos instrumentos essenciais para conquista da consciência coletiva. Não aquele modelo ideologizado, mantenedor e reprodutor de opressões, mas uma educação crítica e processual, que na perspectiva gramsciana, deve considerar os conhecimentos já existentes e enxergar que todos são intelectuais. Educação que, de forma dialética, cria estratégias reflexivas capazes de ampliar a criticidade e potencializar grupos historicamente excluídos a exercerem o protagonismo, assumindo posição contra-hegemônica na esfera da correlação de forças presentes nas relações sociais. Trazemos a universidade para este palco, entendendo-a como instituição de natureza excludente e instrumentalizada para o acúmulo de capital, que precisa colocar-se no lugar inverso, ou seja, mostrar-se compromissada com mudanças sociais tratando ciência como parte do conhecimento coletivo construído historicamente.

Defendemos, portanto, a importância de se buscar instrumentos capazes de questionar os fundamentos que alimentam a manutenção de desigualdades. Há uma miríade de caminhos possíveis, o nosso foi a extensão universitária, que se deu a partir da execução do projeto Aproxima-Ação. A experiência comprovou o quanto a educação em Direitos Humanos pode ser um instrumento importante para tecer mediações entre universidade e comunidade. Essa experiência nos aproximou do que Gramsci chama de difusão e socialização de verdades já descobertas, as quais devem ser transformadas em base de ações vitais no processo da construção de uma nova cultura, que a nosso ver, deve esforçar-se para superar o patriarcado, o racismo e todas as formas de alienação que mantém as relações opressivas e exploratórias em esferas objetivas e subjetivas. A ênfase na esfera da multiplicação dos conhecimentos abordados também gerou processos importantes no que tange a defesa dos Direitos Humanos, entendendo-os como direitos conquistados historicamente por lutas coletivas. 
As ações educativas centraram-se no desenvolvimento de reflexões teórico-críticas acerca da realidade, estimulando a participação política, entendendo os participantes como sujeitos históricos e sociais. Pudemos vivenciar a práxis entre os conceitos gramscianos e concepções sobre sujeito em ações do cotidiano, o que nos leva a defender que o público da extensão universitária não pode ser visto como alvo, mas sim como parte, como protagonistas que devem ser envolvidos nos processos de construção das propostas. Reforçamos que nossa concepção se centra em um entendimento de que os sujeitos da extensão universitária são todos os envolvidos, ou seja, professores, estudantes e comunidade, os quais dialeticamente propiciam a troca de conhecimentos, somos todos sujeitos singulares e coletivos. E como poetiza Roberta Estrela D'Alva, "se Zumbi somos nós, não é mais pessoal", a luta é coletiva.

\section{Referências bibliográficas}

Almeida, S. (2018). O que é racismo estrutural? Letramento.

Almeida, C. N. E.; Reis, H. E. (2018). A educação em direitos humanos como ferramenta de consolidação e expansão dos direitos humanos. $R I D H, 6,45-59$.

Achille, M. (2016). Necropolítica. Arte \& Ensaios, 32.

Berth, J. (2019). Empoderamento. Pólen.

Borges, A. (s/f). Slam: Conheça O Movimento Que Promove Encontros E Batalhas De Poesias Faladas E Está Se Popularizando No Brasil. https://www.thebodyshop.com.br/beleza-do-mundo/slam-conheca-o-movimento-que-promove-encontros-e-batalhas-de-poesias-faladas-e-esta-se-popularizando-no-brasil/

Brasil (1988). Constituição da Republica Federativa do Brasil.

- (1990). Estatuto da Criança e do Adolescente.

(2009). Programa Nacional de Direitos Humanos - PNDH-3. Decreto No 7.037.

(2018). Ministério Da Educação Conselho Nacional De Educação Câmara De Educação Superior Resolução $N^{\circ} 7$, de 18 de Dezembro de 2018.

— (2020a). MEC-PROEXT apresentação. http://portal.mec.gov.br/index.php?option=com_content\&view=article\&id=12241\&ativo=488\&ltemid=487/

— (2020b). Assistência Social. Secretaria Especial de Desenvolvimento Social. http://mds.gov.br/assuntos/assistencia-social/unidades-de-atendimento/cras

(2020c). Saúde. https://www.saude.gov.br/noticias/693-acoes-e-programas/41146-centro-de-atencao-psicossocial-caps

Chauí, M. (1996). Conformismo e Resistência: aspectos da cultura popular no Brasil. Brasiliense.

Dagnino, E. (2004). Construção democrática, neoliberalismo e participação: os dilemas da confluência perversa. Política e Sociedade, 5, 139-164.

D'Alva, R. E. (s/f). Se tentarem te derrubar. https://www.youtube.com/watch?v=tZ6t8IQWONw

Davis, A. (2018). A liberdade é uma luta constante. Boitempo.

Duarte, M. (s/f). Des/ocamento Poesia Manifesto. https://www.youtube.com/watch?v=8z-gyDkQH6k

Evaristo, C. (s/f). É tempo de se aquilombar. https://www.xapuri.info/cultura/tempo-de-nos-aquilombar/

Fanon, F. (2005). Os condenados da Terra. UFJF.

Fraga, P. C. E.; Lunianelli, J. A. S. (2003). Jovens em tempo real. DPA.

Freire, P. (1979). Conscientização: teoria e prática da libertação. Cortez \& Moraes.

Gohn, M. Da G. (1997). Teoria sobre os movimentos sociais. Edições Loyola. 
Gorender, J. (2016). O escravismo colonial. Expressão Popular; Fundação Perseu Abramo.

Gramsci, A. (1978). 1891- 1937. Obras escolhidas. Martins Fontes.

(1984). Concepção Dialética da História. Civilização Brasileira.

(1995). Os intelectuais e a organização da cultura. Civilização Brasileira.

Harvey, D. (2004). Condição Pós-Moderna: uma pesquisa sobre as Origens da Mudança Cultural. Edições Loyola.

Moura, C. (1987). Os quilombos e a rebelião negra. Brasiliense.

Ridenti, M. (1994). Classes sociais e representação. Cortez.

Rocha, A. P. (2000). Hip Hop: cultura e resistência que explode no interior paulista. Trabalho de Conclusão de Curso (Graduação em Serviço Social) UNESP.

(2005). Palco de conflitos: escola pública no capitalismo, aparelho hegemônico ou instrumento de contra-hegemonia? Dissertação (Mestrado em Educação), UEM.

(2012). Trajetórias de adolescentes apreendidos como "mulas" do transporte de drogas na região da fronteira (Paraná) Brasil - Paraguai: exploração de força de trabalho e criminalização da pobreza. 2012.396 f. Tese Doutorado em Serviço Social, UNESP.

(2013). Proibicionismo e a criminalização de adolescentes pobres por tráfico de drogas. Revista Serviço Social \& Sociedade, (115), 561-580.

(2018). Relatório Final da Pesquisa "Prisão Provisória de Jovens pelo crime de tráfico de drogas após a realização das Audiências de Custódia em Londrina/PR". Desenvolvida durante o Estágio de Pós Doutoramento no Programa de Pós Graduação em Serviço Social da ESS-UFRJ.

(2020). O Juvenicídio brasileiro: racismo, guerra às drogas e prisões. EDUEL: Londrina, 2020. (PRELO)

Rocha, A. P. e Santos, J. F. (2019). Racismo e Seletividade Penal: história ocultada por mitos ideologizados. In Amaro, S. e Oliveira, E. R. Sim, o racismo existe! Nova Práxis

Trindade, J. D. De L. (2011). Os direitos humanos: para além do capital. Prefácio. In Brites, C. M. e Forti, V. (Orgs.). Direitos humanos e serviço social: polêmicas, debates e embates (pp. 11-28). Lumen Juris,

Wacquant, L. (2013). Punir os pobres: a nova gestão da miséria nos Estados Unidos. Revan.

Willians, E. (2012). Capitalismo e escravidão. Companhia das Letras. 